\title{
Research on Numerical Simulation of Profile in Bei 301 Block
}

\author{
Li Jing \\ (Research Institute of Petroleum Exploration and Development, Daqing Oil Field, Heilongjiang , \\ Daqing , 163712) \\ 9lijing@163.com \\ Corresponding Author: Jing Li
}

Keywords: Numerical simulation; history match; profile control program

\begin{abstract}
By researching the development process and the status quo in Bei 301 block, this paper sets the three-dimensional geological model, fits the actual production data through using numerical simulation software, and determines the distributions of remaining oils ultimately. On this basis, this article designs the profile program that is shallow profile and evaluates the profile effects, which makes the applications of work fields more scientific.
\end{abstract}

\section{Reservoir Development Survey}

Huhe nuoren oilfield Bei 301 block lies in Inner Mongolia, Hulun Buir League, Xin Barag Right Banner, Buir sum (township) territory. The tectonic position belongs to the Baer lake depression Huhe -2tectonic, the Hailar basin. Oil geological exploration in Hailar basin began in 1958, and in the second half of 2003, the block was gradually put into development, with a $200 \times 200 \mathrm{~m}$ square well pattern, which was based on a flexible layout well, and the quantity of oil well is 52, and the quantity of injection well is 22 . The number of the oil layer in which average single well drilling is 14 , effective thickness is $38.5 \mathrm{~m}$, comprehensive water cut rate is $1.2 \%$, formation pressure is 10.20MPa and total pressure difference is $-1.58 \mathrm{MPa}$. The use of geological reserves is $1166 \times 10^{4} \mathrm{t}$, the use of an area is $3.8 \mathrm{~km}^{2}$, the actual average daily output of single well is $12 \mathrm{t}$ and the annual production of crude oil is $20.7 \times 10^{4} \mathrm{t}$. With the continuous development of the 301 blocks, the increase of total oil production and the decrease of reservoir pressure, the water cut of oil wells increases rapidly and production rapidly declines. After water injection, the oil well is effective and the pressure and the output are rising. Because the great difference of the reservoir permeability causes the injection of water into the fast, water flooding effect is poor.

\section{Establishment of simulation model}

\subsection{Establishment of geological model}

According to the geological and plane distribution characteristics of Bei 301 block, applying the Petrol geological modeling software, this article models this block. This article uses the "curved surface" corner point grid system to model geologically the target well group in the Bei 301 block area. In the target area, the grid is divided into 35 trellis in the $\mathrm{X}$ direction, 35trellies in Y direction, and into 25 layers the vertical direction, and the total grid number is 72600 (see Figure 1). Because the interval is not an independent block, therefore, the reserves and production of wells in accordance with well controlled areas were properly split, and splitting factor is 0.5. 


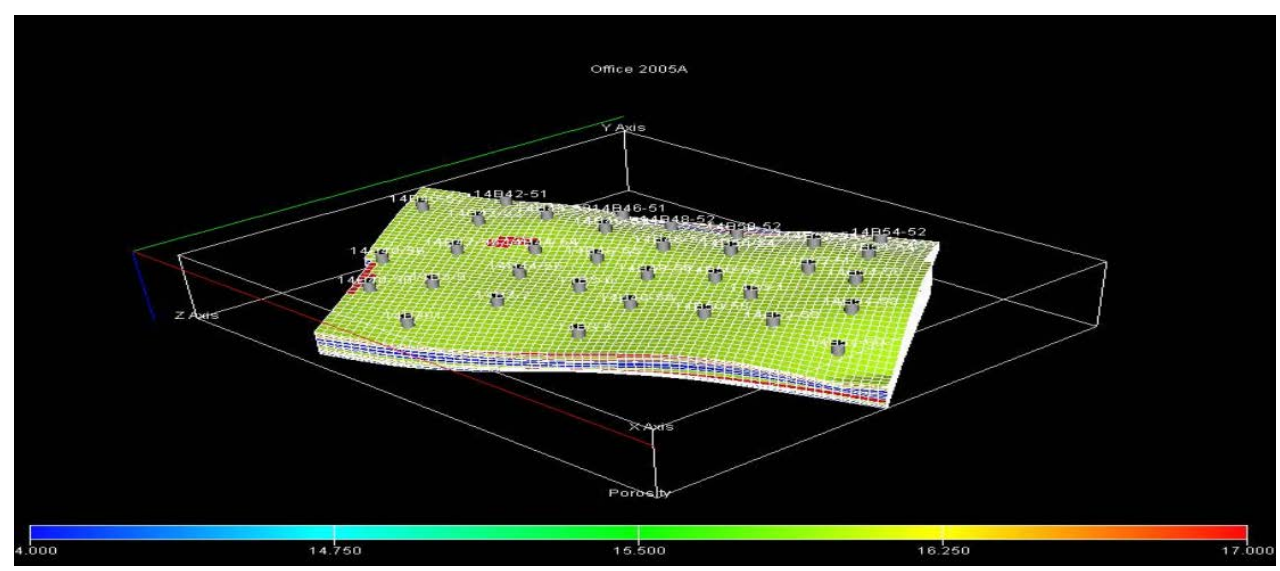

Figure 1 Geological model in Bei 301 block

\subsection{Establishment of fluid model}

The reservoir in the Bei 301 block belong to the black oil model with no gas cap, the reservoir parameters are shown in Table 1 . The temperature range of the reservoir is $48.9 \sim 55.6^{\circ} \mathrm{C}$, and the actual temperature gradient is $3.89 \sim 4.11^{\circ} \mathrm{C} / 100 \mathrm{~m}$, and the average temperature gradient is 3.99 $/ 100 \mathrm{~m}$.

\begin{tabular}{c|ccccc}
\multicolumn{7}{c}{ Table 1 Fluid parameters in the Bei 301 block } \\
\hline $\begin{array}{c}\text { Saturation } \\
\begin{array}{c}\text { Pressure } \\
(\mathrm{MPa})\end{array}\end{array}$ & $\begin{array}{c}\text { Crude Oil } \\
\text { Viscosity } \\
(\mathrm{MPa} \cdot \mathrm{s})\end{array}$ & Volume Factor & $\begin{array}{c}\text { Compressibility } \\
\text { Factor } \\
\left(\times 10^{-4} 1 / \mathrm{MPa}\right)\end{array}$ & $\begin{array}{c}\text { Primary Oil } \\
\text { and Gas Ratio } \\
\left(\mathrm{m}^{3} / \mathrm{t}\right)\end{array}$ & $\begin{array}{c}\text { Relative } \\
\text { Density }\end{array}$ \\
\hline 3.69 & 2.36 & 1.0945 & 9.33 & 28.5 & 0.7714 \\
\hline
\end{tabular}

According to the built model, the simulation area is initialized, the simulation results of the calculation of reserves and the initial pressure are showed Table 2.

Table 2 Geological reserves and formation parameters of the simulation layer

\begin{tabular}{c|ccccc}
\hline $\begin{array}{c}\text { Geologial } \\
\text { Reserve } \\
\left(\times 10^{4} \mathrm{t}\right)\end{array}$ & $\begin{array}{c}\text { Stratum initial } \\
\text { water content } \\
\left(\mathrm{m}^{3}\right)\end{array}$ & $\begin{array}{c}\text { Average oil } \\
\text { saturation } \\
(\%)\end{array}$ & $\begin{array}{c}\text { Average water } \\
\text { saturation } \\
(\%)\end{array}$ & $\begin{array}{c}\text { Average } \\
\text { permeabilit } \\
\text { y } \\
(\mathrm{md})\end{array}$ & $\begin{array}{c}\text { Average } \\
\text { porosity } \\
(\%)\end{array}$ \\
\hline 594.8198 & 6030641 & 54.06 & 45.94 & 26.4615 & 18.41 \\
\hline
\end{tabular}

\section{History Matching}

At present, the running process of numerical simulation software is to use the production of historical dynamic monitoring data of oil and water wells. Through the historical production data of the reservoir amend the geological model, the final uses of reserves, pressure, output and water and other indicators of the degree fit to evaluate the credibility of the model ${ }^{[1-2]}$.

The error of the fitting result of the geological reserves is $0.06 \%$. Cumulative oil fitting error is within $1 \%$. The single well fitting is achieved by modifying the permeability and the local area adjusting the permeability and the production fluid profile. Numerical simulation requires that the history of water flooding is basically consistent with the actual situation, and the number of wells exceeds the total number of wells $2 / 3$. If the wells are not simulated rightly, considering the correctness of geological stratification, the full geological model is carried out reasonably ${ }^{[3-4]}$.

\section{Remaining oil distribution}

Until March 2008, the degree of recovery of the simulation block is $7.63 \%$. From the oil saturation distribution figure of each small layer can also be seen, there are the remaining oil distribution of small contiguous layer. From the plane, the remaining oil distribution of the well group in the Bei 301 block is relatively uneven. In Nan Tun group 11, 13 small layer, injected water to the four direction advance more uniformly and the pace is fast, the affected area is broad, and oil saturation in connected regions is relatively low. From the reservoir edge, the advancing edge water can be seen, so the edge well has edge water energy driven in a certain extent. Nan Tun group 4, 6 
small layers advance slowly, oil saturation is generally high, and two small layers have good exploration potentially, especially around away from injection wells, oil saturation is at around $50 \%$.

\section{Profile control scheme design}

\subsection{Profile control well selected}

Selecting the profile control wells mainly according to the following principles:

1. Water injection well located in the high water cut comprehensively, lower production level and higher residual saturation;

2. Water injection well connected with the well group better;

3. Water injection well with water absorption and water injection in good condition;

4. Water injection well with uniform water injection profile and a strong water absorption layer heavily;

5. Water injection well with the thickness of the reservoir, the development of sand bodies, the vertical heterogeneity is serious, the use of the situation is different, the injection water is fast;

6. Water injection well with good cementing quality, no series of slots and no phenomenon of inter layer strand leakage.

According to the above principles, 5 wells are choosed,14B3-1、14B44-54、14B40-52、14B48-56、 14B52-54.

\subsection{Profile control scheme design}

Based on the mathematical model of residual oil distribution, different schemes are designed to profile control well layer, the results are shown in Table 3.

Table 3 Numerical simulation selected layers results

\begin{tabular}{cc|ccc}
\hline $\begin{array}{c}\text { Optimized profile control } \\
\text { scheme }\end{array}$ & Scheme 1 & Scheme 2 & Scheme 3 \\
\hline 14B3-1 & & 8.9 .11 .13 & \\
14B44-54 & 17.18 & & 11.12 .17 \\
14B40-52 & & & 4.11 .12 .16 \\
14B52-54 & 4.16 .20 & & \\
\hline
\end{tabular}

\subsection{Profile control effect prediction}

Numerical simulation is applied to profile control wells, using the preferred profile control parameter to design profile control measures to predict the effect of profile control.

Table 4 Numerical simulation results of profile control wells

\begin{tabular}{c|ccccc}
\hline Battery of wells & $14 \mathrm{~B} 3-1$ & $14 \mathrm{~B} 44-54$ & $14 \mathrm{~B} 40-52$ & $14 \mathrm{~B} 48-56$ & $14 \mathrm{~B} 52-54$ \\
\hline Oil increment(t) & 803.49 & 3436.96 & 1369.68 & 2529.94 & 1282.40 \\
$\begin{array}{c}\text { Water cut reducing } \\
\text { value(\%) }\end{array}$ & 6.4 & 5.8 & 4.6 & 5.3 & 3.4 \\
\hline
\end{tabular}

From table 4, it can be seen that, because of the different reservoir of physical properties, there is also different in the amount of oil.

\section{Conclusions}

(1) With the continuous development of the Bei 301 block, the increase of the total oil production and the decrease of reservoir pressure, the water cut of oil wells is increasing rapidly and production is decreasing rapidly. In order to control the water cut rising rate, profile control is carried out.

(2) Through the simulation of the profile control of the well group, the average oil content of the single well after profile control is $200 \mathrm{t}-684 \mathrm{t}$, the water cut is $4 \% \sim 6 \%$, and the effect is obvious. 


\section{Reference}

[1] Wei Pengju, Wei Wei, Du Xiaofeng,etc. Study on Numerical Simulation of mining technology and the low permeability bottom water reservoir[J]. Oil-Gas field Surface Engineering, 2009, 28(8):32-33.

[2] Zhang Liehui. Basic principles of numerical simulation of oil gas reservoir[M]. Beijing: Petroleum Industry Press, 2005.

[3] Xu Yiwei. Numerical simulation of low permeability reservoir[J]. Journal of Jianghan Petroleum Institute, 2003, 25(4):109-110.

[4] Han Dakuang. Numerical simulation basis of reservoir[M]. Beijing: Petroleum Industry Press,1993. 